\title{
Preferences and Priorities for Relapsed M
Myeloma Treatments Among Patients and Caregivers in the United States
}

\author{
Daniel Auclair $\mathbb{D}^{1 *}$, Carol Mansfield $\mathbb{D}^{2}{ }^{2 *}$, Mark A Fiala ${ }^{3} *$, Ajai Chari ${ }^{4}$, Craig E Cole ${ }^{5}$, \\ Jonathan L Kaufman ${ }^{6}$, Gregory J Orloff ${ }^{7}$, David S Siegel $\mathbb{D}^{8}$, Jeffrey A Zonder ${ }^{9}$, Brennan Mange ${ }^{2}$, \\ Jennifer Yesil', Mehul Dalal ${ }^{10}$, Joseph R Mikhael ${ }^{11}$ \\ 'Department of Research, Multiple Myeloma Research Foundation, Norwalk, CT, USA; ${ }^{2}$ RTI Health Solutions, Research Triangle Park, NC, USA; \\ ${ }^{3}$ Division of Hematology \& Oncology, Washington University School of Medicine, St. Louis, MO, USA; ${ }^{4}$ Icahn School of Medicine, Mount Sinai \\ Hospital, New York, NY, USA; ${ }^{5}$ Department of Medicine, MSU Breslin Cancer Center, Lansing, MI, USA; ${ }^{6}$ Winship Cancer Institute, Emory University \\ School of Medicine, Atlanta, GA, USA; ${ }^{7}$ Virginia Cancer Specialists, Fairfax, VA, USA; ${ }^{8}$ John Theurer Cancer Center, Hackensack University Medical \\ Center, Hackensack, NJ, USA; ${ }^{9}$ Division of Clinical Hematology-Oncology, Barbara Ann Karmanos Cancer Institute, Detroit, MI, USA; ${ }^{0}$ Millennium \\ Pharmaceuticals, Inc., a wholly owned subsidiary of Takeda Pharmaceutical, Company Ltd, Cambridge, MA, USA; "Translational Genomic Research \\ Institute, City of Hope Cancer Center, Phoenix, AZ, USA
}

*These authors contributed equally to this work

Correspondence: Daniel Auclair, AstraZeneca Oncology R\&D| Hematology, 35 Gatehouse Drive, Waltham, MA, 0245I, USA,

Email daniel.auclair@astrazeneca.com

Introduction/Background: This study aimed to describe patient and caregiver preferences for treatments of relapsed or refractory multiple myeloma (MM).

Materials and Methods: A survey including discrete-choice experiment (DCE) and best-worst scaling (BWS) exercises was conducted among US patients with relapsed or refractory MM and their caregivers. The DCE included six attributes with varying levels including progression-free survival (PFS), toxicity, and mode and frequency of administration. In addition, the impact of treatment cost was assessed using a fixed-choice question. The BWS exercise included 18 items (modes and frequency of administration, additional treatment convenience, and toxicity items). The survey was administered online to patients recruited from the Multiple Myeloma Research Foundation CoMMpass study (NCT01454297).

Results: The final samples consisted of 94 patients and 32 caregivers. Avoiding severe nerve damage was most important to patients, followed by longer PFS. Caregivers considered PFS to be the most important attribute. We estimate that a third or more of patients were cost-sensitive, meaning their treatment preference was altered based on cost implications. Caregivers were not cost-sensitive. The three most bothersome treatment features in the BWS exercise were risk of kidney failure, lowering white blood cell counts, and weakening the immune system.

Conclusion: Patients with relapsed or refractory MM and their caregivers consider many factors including efficacy, toxicity, mode/ frequency of administration, and cost in their decisions regarding treatment options. The study provides a basis for future Research on patient and caregiver treatment preferences, which could be incorporated into shared decision-making with physicians.

Keywords: discrete choice experiment, preference, patient, caregiver, multiple myeloma

\section{Introduction}

Multiple myeloma (MM), a neoplasm of the plasma cell affecting an estimated 130,000 US individuals, is the second most common hematologic malignancy. ${ }^{1,2}$ Despite recent advancements in therapeutic options, MM remains incurable and is associated with considerable symptom burden and impairments in health-related quality of life (HRQoL). ${ }^{3}$ In particular, MM and its treatment can cause debilitating complications, including bone pain and fracture, renal insufficiency, cardiovascular complications such as venous thromboembolism and anemia, and peripheral neuropathy. ${ }^{4-7}$ 
Patients with relapsed or refractory MM are faced with a variety of viable therapeutic options, such that patients and physicians must together consider tradeoffs among the attributes related to efficacy, tolerability, and other aspects of HRQoL of potential therapies in making treatment decisions that reflect patients' preferences, values, and priorities. However, relatively little is known about the preferences of patients and their caregivers in terms of myeloma treatments. Historically, there has been a disconnect between the preferences of physicians and their patients, ${ }^{8}$ and better defining patients' preferences can help to bridge that gap.

In addition to the patients themselves, it is important to understand the preferences of caregivers for those with MM, friends or family members who provide physical and/or emotional care, who also bear the burden of MM and often have a key role in treatment decision-making. Due to the level of symptomology related to $\mathrm{MM}$ and the relatively high treatment burden, ${ }^{9}$ caregivers for patients with MM are even more involved in patient care than other malignancies. ${ }^{10}$ But little is known about their preferences for MM treatment.

The objective of this study was to describe the preferences for treatments for relapsed or refractory MM among patients and their caregivers.

\section{Materials and Methods}

A web-based discrete-choice experiment (DCE) and best-worst scaling (BWS) survey was employed to quantitatively assess patients' preferences over a set of MM treatment attributes. Computer tablets were provided to participants.

\section{Study Population}

Convenience samples of patients and caregivers were recruited from sites participating in the Multiple Myeloma Research Foundation CoMMpass study (NCT01454297), a longitudinal study that has enrolled 1150 patients with MM across 91 sites in the United States (US), Canada, and Europe to evaluate clinical parameters, HRQoL, and health care resource utilization over at least 5 years of treatment. ${ }^{11}$ For this survey, patients were invited from four CoMMpass sites to complete the online preference survey: Virginia Cancer Specialists, Arlington, Virginia; Washington University School of Medicine, St. Louis, Missouri; Mount Sinai Hospital, New York, New York; and Hackensack University Medical Center, Hackensack, New Jersey. The CoMMpass Patient Support Center also reached out directly to CoMMpass patients to invite them to take the survey. The survey was programmed and administered online by GfK, a market research firm.

Eligible respondents for the patient survey, participating in the CoMMpass study at the time of recruitment, had a physician-confirmed diagnosis of MM, and had been documented as having at least one relapse. Eligible respondents for the caregiver survey were self-reported caregivers, of a person who met the criteria of the patients recruited for the study but not necessarily of patients surveyed within the study. Eligible respondents were adults aged 18 years or older, residents of the US, able to read and understand English, and able to provide informed consent.

\section{Survey Instrument}

The survey instrument was developed following good research practices. ${ }^{12}$ Attribute selection and descriptions for both the DCE and BWS exercises were informed by four focus groups conducted with convenience samples of a total of 12 patients with MM and 11 caregivers of patients with MM. Focus group participants were recruited by Snow Companies, a patient-to- patient education, awareness, and word-of-mouth marketing agency. The focus groups identified efficacy, mode and frequency of administration, and several side effects as the most important treatment features. From the list generated in the focus groups, clinicians and treating physicians on the Multiple Myeloma Research Foundation Steering Committee provided input on the attributes and attribute descriptions for the DCE based on their experience and the data available from clinical trials for the therapies of interest. The attributes selected for the DCE reflected clinically relevant endpoints that were identified as important by patients and caregivers. The levels within each attribute were selected based on results from previous clinical trials for comparability with currently available treatment profiles of proteasome inhibitors (bortezomib, carfilzomib, and ixazomib) immunomodulatory drugs (lenalidomide, pomalidomide), and monoclonal antibodies (elotuzumab and daratumumab). However, none of the agents were modeled specifically within the DCE or BWS instrument. Some attributes such as gastrointestinal toxicities nausea, vomiting, diarrhea, and constipation, 
and route and frequency of administration were combined as levels within an attribute. This does limit the interpretation of the relative importance of each attribute/level to improve the efficiency of the DCE as the preference weights calculated from the DCE, as discussed further in the statistical analysis section, pertain to the attribute as a whole and not for individual levels of the attribute. However, this was done to improve efficiency and power.

To pretest the survey instrument for comprehension and completeness, face-to-face, semistructured qualitative interviews were conducted with convenience samples of 31 patients and 24 caregivers. The first 20 patients and 9 caregivers were recruited through Hackensack University Medical Center, Virginia Cancer Specialists, and the Washington University School of Medicine. Final pretests with 11 patients and 15 caregivers were recruited through L\&E Research. Based on participant feedback, changes were made to the survey text, questions, and attribute and level descriptions. Such changes included clarifying clinical concepts (eg, progression-free survival [PFS], symptoms experienced at MM diagnosis) to be presented in patient-friendly terms, specifying treatment frequency in the descriptions of treatment characteristics, refining the descriptions of the risks of low platelets and low white blood cell counts, and adding questions about patient demographics in the caregiver questions. The data from the focus groups and pretests of the survey instruments were not included in the analysis.

In each DCE question, respondents were asked to choose between two hypothetical, experimentally designed treatments. Figure 1A presents an example DCE question from the patient survey, Figure 1B an example of BestWorst Scaling Question, and Supplementary Table 1A presents the treatment attributes, attribute levels, and descriptions of the attribute levels provided to respondents evaluated in the DCE. A fractional factorial experimental design was constructed with Sawtooth software using a D-efficient algorithm, ${ }^{13-17}$ which was evaluated for level balance and correlation. The full fractional design contained 40 DCE questions, which were used to create five blocks of eight DCE questions each. Respondents were randomly assigned to one of these blocks.

To capture information about the role of cost in treatment choice, a fixed-choice question was shown to respondents after the conclusion of the experimentally determined series of DCE questions. The fixed-choice question was presented in the same format as the DCE questions but asked respondents to choose between two medicine profiles where out-ofpocket cost was added to the attributes in the DCE (see Supplementary Table 1A).

The focus groups identified more treatment features than could be accommodated in the DCE. To provide an additional source of information on treatment preferences for a larger set of outcomes, a BWS exercise assessing additional treatment features also was included in the survey. Respondents were given three medication attributes and were asked to choose the one that bothered them the least (Best) and the one that bothered them the most (Worst). Supplementary Table 1B presents an example BWS question from the patient survey. The BWS exercise included 18 items (the modes and frequency of administration included in the DCE, additional treatment convenience items, mild and serious adverse events, and treatment side effects). The experimental design for the BWS questions was also created using Sawtooth software. The full BWS experimental design contained 45 questions, which were divided into five blocks of nine questions. Respondents were randomly assigned to one of the five blocks.

In addition to the DCE and BWS questions, the survey instrument included questions about respondents' demographic characteristics, patient experiences with $\mathrm{MM}$ or caregiver experiences caring for a patient with MM. Comprehension questions testing respondents' understanding of the treatment attributes and levels were also included.

\section{Statistical Analyses}

The analysis sample included all respondents who provided consent and answered at least 1 DCE choice question. Responses to the survey items and respondent characteristics were summarized descriptively.

A random-parameters logit (RPL) regression model was used to analyze the patient choice data collected in this DCE. RPL models avoid potential estimation bias from unobserved preference heterogeneity. ${ }^{18,19}$ A conditional multinomial logit regression model was used to analyze the caregiver choice data collected in this due to the small number of caregivers in the sample.

Although the conditional logit model does not control for unobserved preference heterogeneity, the model is recommended and is widely used for DCE analysis. ${ }^{20}$ 
A

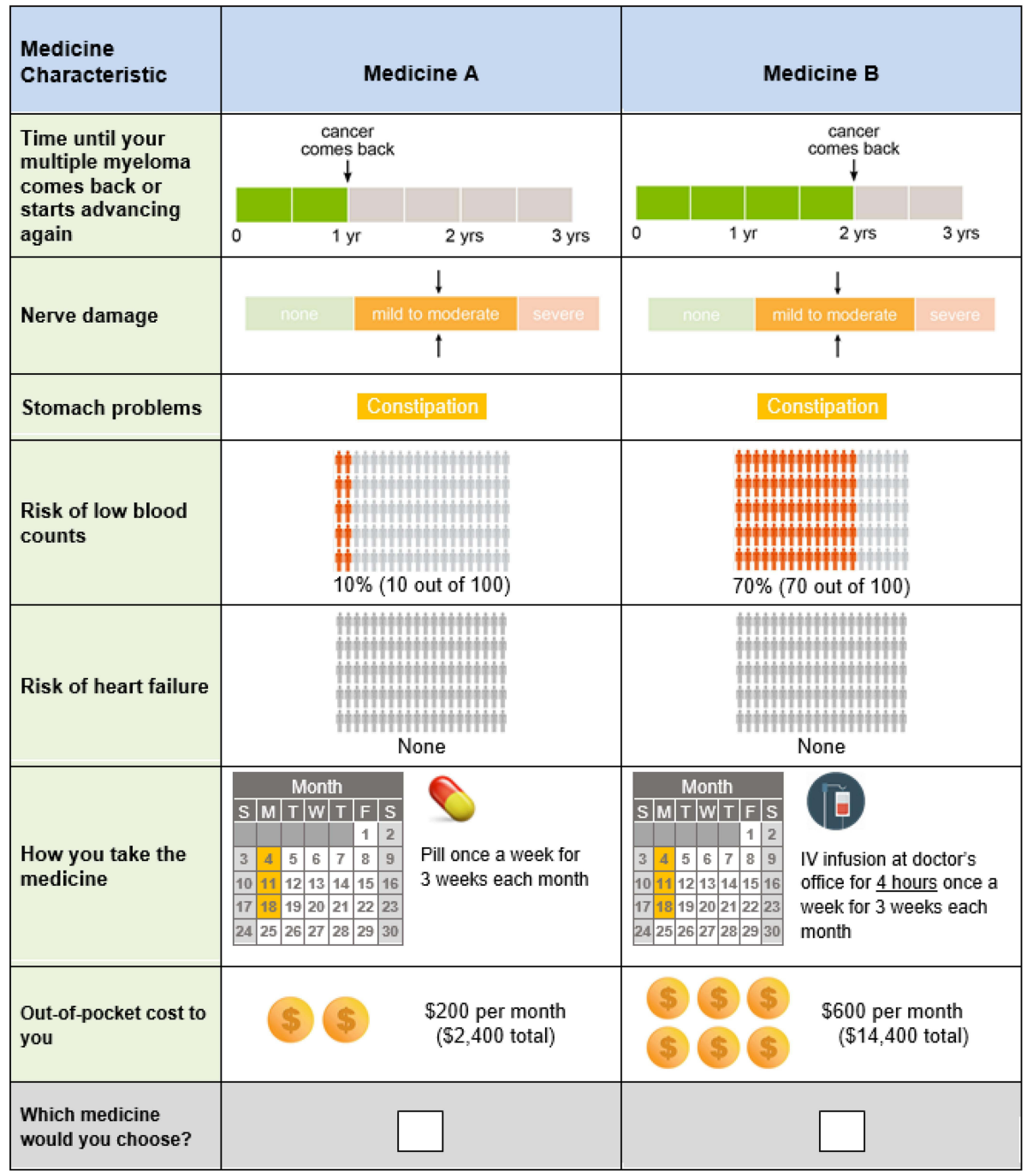

B

\begin{tabular}{|c|c|c|}
\hline $\begin{array}{l}\text { I would be } \\
\text { bothered by } \\
\text { this the } \\
\text { MOST }\end{array}$ & Medicine Characteristics & $\begin{array}{l}\text { I would be } \\
\text { bothered by } \\
\text { this the } \\
\text { LEAST }\end{array}$ \\
\hline ( & $\begin{array}{l}\text { Treatment weakens your immune system and you get sick } \\
\text { more often }\end{array}$ & 0 \\
\hline 0 & $\begin{array}{l}\text { Having trouble working at your job or at home during } \\
\text { treatment }\end{array}$ & 0 \\
\hline 0 & $\begin{array}{l}\text { Treatment damages kidneys and increases the risk of } \\
\text { kidney failure }\end{array}$ & e \\
\hline
\end{tabular}

Figure I Example questions from the patient survey. (A) Example DCE question with fixed-profile choice question from the patient survey. (B) Example best-worst scaling question from the patient survey. 
The RPL and conditional logit models yield preference weights that can be interpreted as the relative strength of preference for each attribute level. The scale of these weights is arbitrary and is not directly interpretable, but morepreferred outcomes have higher preference weights. The preference weights can be used to calculate the conditional relative importance estimates for the features associated with MM medicines over the range of levels for each attribute. A conditional relative importance estimate for a feature is the difference between the most-preferred level of that feature and the least-preferred level of that feature. Conditional relative importance scores were scaled so that the most important attribute is equal to 10 , and all other scores are relative to that of the most important attribute.

To evaluate the impact of cost on the selected set of treatment profiles, the preference weights from the RPL and conditional logit models were used to estimate the probability that a respondent would select each treatment profile when cost was not included. The predicted probability of selecting each profile in Figure 1A was compared with the percentage of the sample that selected each profile when cost was included in the fixed-choice question.

A relative score was calculated for each item in the BWS exercise by subtracting the number of times a feature was chosen as least bothersome from the number of times it was chosen as most bothersome, then dividing by the total number of times the feature appeared in the design. The score reflects both the overall ranking of the BWS items and the degree of bothersomeness of each item relative to the other items.

\section{Results}

\section{Study Population}

The final samples consisted of 94 patient respondents with MM and 32 caregivers of individuals with MM (but not necessarily of patients surveyed). Patients were an average age of 65 years old, and 59\% were male (Table 1); caregivers were an average age of 63 years old, and $53 \%$ were female (Table 2).

\section{Attribute Importance}

The mean preference weight estimates for each attribute level are presented in Supplementary Figure 1. Of the attributes and their respective levels presented in the survey, the most important to both patients and caregivers were severe nerve damage and PFS (Figure 2). Patients considered avoiding severe nerve damage to be most important of the two. Caregivers considered the increase PFS to be most important, although the differences between nerve damage and PFS were not statistically significant for caregivers. The least important attribute to patients was risk of heart failure. The least important attribute to caregivers was gastrointestinal problems. The results also suggest patients and caregivers may prefer oral drugs over other modalities.

\section{Impact of the Cost on Preference}

In the fixed-choice question (Figure 1A), Medicine A had lower PFS than Medicine B but also had a lower risk of low blood counts, was administered as a weekly pill, and cost $\$ 400$ less per month than Medicine B. Using the RPL and conditional logit models to predict the probability that respondents would select Medicine A or Medicine B when cost was not included, the average patient respondent had a 21.8\% (95\% CI, 4.0-39.7\%) chance of selecting Medicine A. Based on this, we would have expected that approximately 4 to 38 patients would select Medicine A if cost data was not included. However, 62 patients (68.1\% [95\% CI, 58.7-77.6\%]) chose Medicine A when cost was included. This suggests that cost influenced the decision of some patients. In the caregiver survey, we would have expected that 12 to $23(64.9 \%$ (95\% CI, 25.8-100.0\%) would have chosen Medicine A if cost data was not included. When cost was included, 17 caregivers (54.8\% [95\% CI, 37.3-72.4\%]) chose Medicine A. Therefore, increased cost did not seem to influence the decision of caregivers.

\section{Most Bothersome Features}

Patients and caregivers both considered features that represented treatment-related risks to be among the most bothersome features in the BWS exercise. For patients (Table 3), the three most bothersome treatment features were kidney damage, reduced white blood cell counts, and a weakened immune system. For caregivers (Table 4), the three most 
Table I Respondent Characteristics - Patients

\begin{tabular}{|c|c|c|}
\hline Question & Statistic or Category & Total $(\mathbf{N}=94)$ \\
\hline \multirow[t]{3}{*}{ Age (years) } & Mean (SD) & $64.9(9.8)$ \\
\hline & Number over 55 years old & 79 (84.0\%) \\
\hline & Minimum, maximum & 32,88 \\
\hline Gender & Female & 39 (4I.5\%) \\
\hline \multirow[t]{8}{*}{ Race } & American Indian or Alaska Native & $\mathrm{I}(\mathrm{I} . \mathrm{I} \%)$ \\
\hline & Asian Indian & I (I.I\%) \\
\hline & Black or African American & $9(9.6 \%)$ \\
\hline & Chinese & $\mathrm{I}(\mathrm{I} . \mathrm{I} \%)$ \\
\hline & Filipino & $\mathrm{I}(\mathrm{I} . \mathrm{I} \%)$ \\
\hline & White & 77 (81.9\%) \\
\hline & Other & $\mathrm{I}(\mathrm{I} .1 \%)$ \\
\hline & Prefer not to share & $5(5.3 \%)$ \\
\hline \multirow[t]{3}{*}{ Ethnicity } & Hispanic or Latino & $\mathrm{I}(\mathrm{I} . \mathrm{I} \%)$ \\
\hline & Not Hispanic or Latino & $88(93.6 \%)$ \\
\hline & Prefer not to share & $5(5.3 \%)$ \\
\hline \multirow[t]{3}{*}{ Current employment status } & Employed full-time & $24(25.5 \%)$ \\
\hline & Employed part-time for reasons not related to MM & $4(4.3 \%)$ \\
\hline & Employed part-time because of MM & $5(5.3 \%)$ \\
\hline \multirow[t]{2}{*}{ Do the following people help take care of you on a daily basis? } & My spouse or partner & $48(51.1 \%)$ \\
\hline & My child & $8(8.5 \%)$ \\
\hline \multirow[t]{5}{*}{ Recruitment site } & CoMMpass Patient Support Center & $25(26.6 \%)$ \\
\hline & Virginia Cancer Specialists & $20(21.3 \%)$ \\
\hline & Washington University School of Medicine & $19(20.2 \%)$ \\
\hline & Mount Sinai Hospital & $20(21.3 \%)$ \\
\hline & Hackensack University Medical Center & $10(10.6 \%)$ \\
\hline Treatment experience & Currently receiving treatment & $82(87.2 \%)$ \\
\hline Years since diagnosis & Mean (SD) & $5.3(3.38)$ \\
\hline
\end{tabular}

bothersome treatment features were kidney damage, weakened bones, and reduced white blood cell counts. Patients and caregivers considered features that were modes of administration to be among the least bothersome features in the BWS given the set of features included.

\section{Discussion}

Recent legislation in the US promotes the inclusion of patient preferences in decision-making at all stages of drug development, the regulatory approval process, and shared decision-making with physicians. ${ }^{21,22}$ With this goal in mind, 
Table 2 Respondent Characteristics - Caregivers

\begin{tabular}{|c|c|c|}
\hline Question & Statistic or Category & Total $(\mathbf{N}=32)$ \\
\hline \multirow[t]{3}{*}{ Age (years) } & Mean (SD) & $62.5(12.8)$ \\
\hline & Number over 55 years old & 24 \\
\hline & Minimum, maximum & 29,83 \\
\hline Gender & Female & $17(53.1 \%)$ \\
\hline \multirow[t]{6}{*}{ Race } & American Indian or Alaska Native & I (3.1\%) \\
\hline & Asian Indian & I (3.1\%) \\
\hline & Black or African American & $3(9.4 \%)$ \\
\hline & White & $26(81.3 \%)$ \\
\hline & Other & I (3.1\%) \\
\hline & Prefer not to share & I (3.1\%) \\
\hline \multirow[t]{3}{*}{ Ethnicity } & Hispanic or Latino & $2(6.3 \%)$ \\
\hline & Not Hispanic or Latino & $28(87.5 \%)$ \\
\hline & Prefer not to share & $2(6.3 \%)$ \\
\hline \multirow[t]{3}{*}{ Current employment status ${ }^{\mathrm{a}}$} & Employed full-time & II (35.5\%) \\
\hline & Employed part-time for reasons not related to MM & $3(9.7 \%)$ \\
\hline & Employed part-time because of MM & 0 \\
\hline \multirow{2}{*}{$\begin{array}{l}\text { How would you describe your relationship with } \\
\text { the person you are caring for? }\end{array}$} & I am caring for my spouse or significant other & 25 (78.1\%) \\
\hline & Other & 7 (21.9\%) \\
\hline \multirow[t]{5}{*}{ Recruitment site } & CoMMpass Patient Support Center & $2(6.3 \%)$ \\
\hline & Virginia Cancer Specialists & $8(25.0 \%)$ \\
\hline & Washington University School of Medicine & $9(28.1 \%)$ \\
\hline & Mount Sinai Hospital & $9(28.1 \%)$ \\
\hline & Hackensack University Medical Center & $4(12.5 \%)$ \\
\hline
\end{tabular}

Note: ${ }^{a}$ One respondent skipped this question; therefore, percentages are calculated out of total non-missing data.

Abbreviations: MM, multiple myeloma; SD, standard deviation.

this study aimed to characterize the preferences of patients with relapsed or refractory MM and their caregivers. It found that patients and caregivers placed the most weight on increasing PFS and avoiding severe nerve damage. The relative importance of these two attributes differed between patients and caregivers, with avoidance of severe nerve damage being the most important attribute to patients and prolonged PFS being the most important attribute to caregivers, although the differences in conditional relative importance are not statistically significant. Both patients and caregivers placed more importance on an increase in PFS from 6 months to 12 months than avoiding mild-to-moderate nerve damage. The results indicate that both patients and caregivers make tradeoffs when it comes to treatments to manage relapsed or refractory MM.

Two recent DCE studies examined preferences for MM treatment among patients in the UK and Australia. ${ }^{23,24}$ In both studies, patients placed significantly more importance on overall survival (OS) than other attributes. However, the 


\section{A Patients $(\mathrm{N}=94)$}

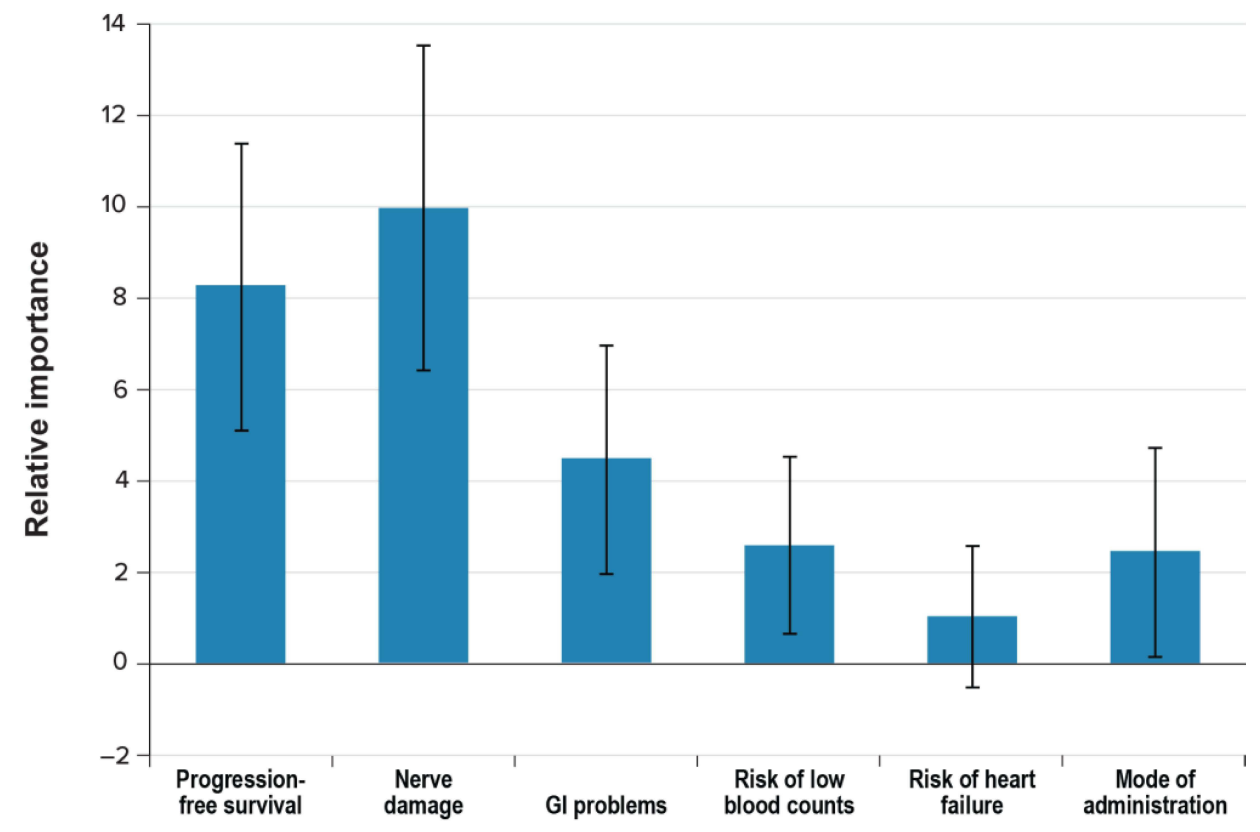

Attribute

\section{B Caregivers $(\mathbf{N}=32)$}

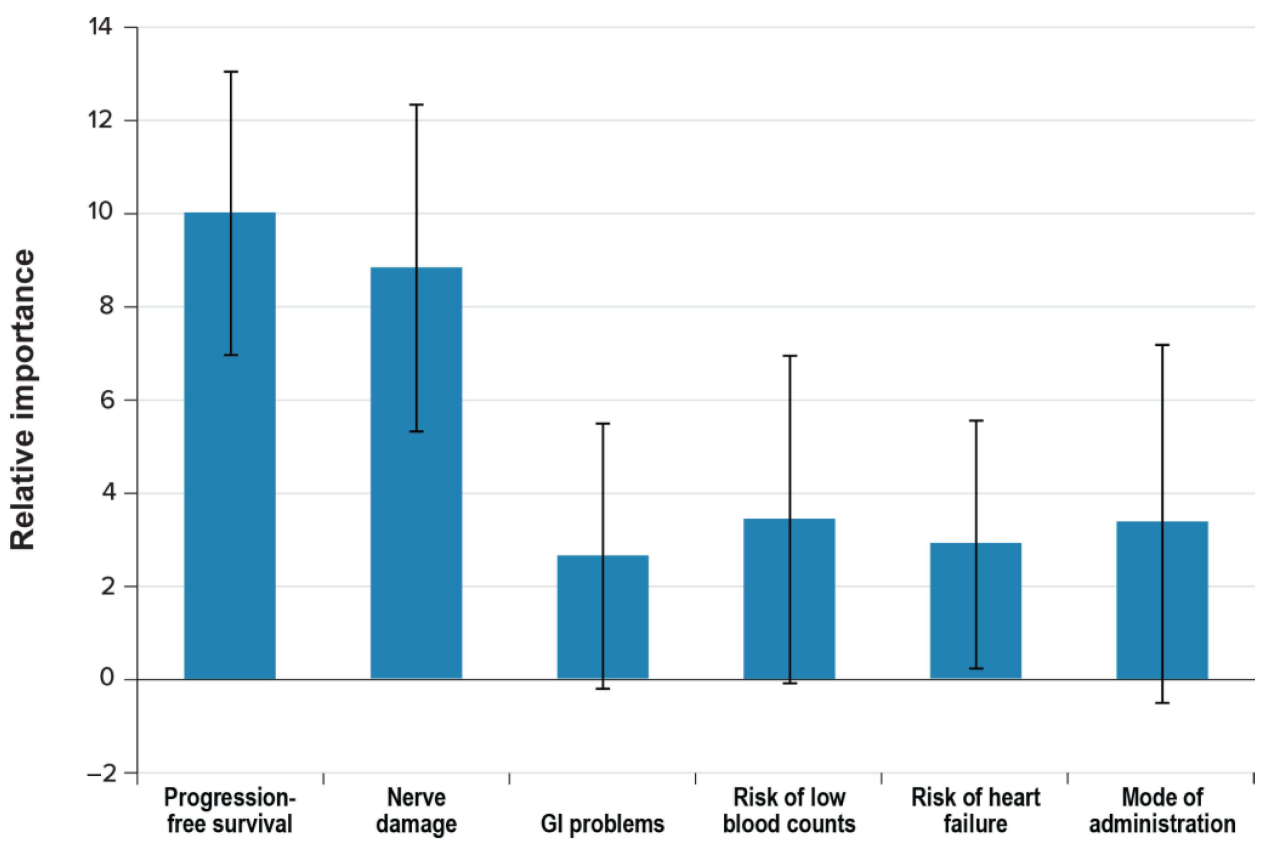

Attribute

Figure 2 Conditional relative importance of a change in each attribute from the least-preferred level to the most-preferred level. (A) Patients. (B) Caregivers. Notes: The vertical bars surrounding each mean preference weight denote the $95 \%$ confidence interval of the point estimate. The levels of each attribute were as followsprogression-free survival: 6 months, 12 months, or 24 months; nerve damage: none, mild to moderate, or severe; Gl problems: none, nausea and vomiting, diarrhea, constipation; risk of low blood counts: none, $10 \%, 25 \%, 70 \%$; risk of heart failure: none, $3 \%, 5 \%$; mode of administration (each for 3 weeks each month): daily pill, weekly pill, weekly injection; weekly 4-hour IV infusion, twice-weekly I-hour IV infusion.

Abbreviation: Gl, gastrointestinal. 
Table 3 Best-Worst Scaling Results - Patients

\begin{tabular}{|c|c|c|c|c|}
\hline Feature & $\begin{array}{l}\text { Frequency Picked } \\
\text { Most Bothersome }\end{array}$ & $\begin{array}{c}\text { Frequency Picked } \\
\text { Least } \\
\text { Bothersome }\end{array}$ & $\begin{array}{l}\text { Number of Times } \\
\text { Item Was Shown }\end{array}$ & $\begin{array}{c}\text { Relative } \\
\text { Score }\end{array}$ \\
\hline \multicolumn{5}{|l|}{ Patients $(\mathbf{N}=94)$} \\
\hline $\begin{array}{l}\text { Treatment damages kidneys and increases the risk of } \\
\text { kidney failure }\end{array}$ & III & 1 & 126 & 0.87 \\
\hline $\begin{array}{l}\text { Treatment lowers white blood cell counts and increases } \\
\text { the risk of serious infection }\end{array}$ & 82 & 12 & 153 & 0.46 \\
\hline $\begin{array}{l}\text { Treatment weakens your immune system and you get } \\
\text { sick more often }\end{array}$ & 68 & 9 & 136 & 0.43 \\
\hline $\begin{array}{l}\text { Needing to go to the hospital to treat a side effect of } \\
\text { the treatment }\end{array}$ & 77 & 26 & 129 & 0.40 \\
\hline $\begin{array}{l}\text { Treatment weakens your bones and increases the risk of } \\
\text { a bone fracture }\end{array}$ & 60 & 14 & 126 & 0.37 \\
\hline $\begin{array}{l}\text { Treatment lowers platelet counts and increases the risk } \\
\text { of bleeding problems }\end{array}$ & 51 & 13 & 126 & 0.30 \\
\hline Feeling exhausted or tired most days during treatment & 66 & 24 & 143 & 0.29 \\
\hline $\begin{array}{l}\text { Having thinking or memory problems for a few weeks } \\
\text { after receiving treatment }\end{array}$ & 71 & 27 & 156 & 0.28 \\
\hline $\begin{array}{l}\text { Changes in mood that may include lack of patience or } \\
\text { nonstop talking for } 2 \text { or } 3 \text { days after each treatment }\end{array}$ & 51 & 36 & 132 & 0.11 \\
\hline $\begin{array}{l}\text { Having trouble working at your job or at home during } \\
\text { treatment }\end{array}$ & 39 & 32 & 150 & 0.05 \\
\hline $\begin{array}{l}\text { 4-hour IV, I time per week for } 3 \text { weeks out of every } \\
\text { month }\end{array}$ & 27 & 44 & 146 & -0.12 \\
\hline $\begin{array}{l}\text { I-hour IV, } 2 \text { times per week for } 3 \text { weeks out of every } \\
\text { month }\end{array}$ & 39 & 59 & 143 & -0.14 \\
\hline $\begin{array}{l}\text { You need to travel } 3 \text { hours roundtrip once a week to } \\
\text { receive your treatment }\end{array}$ & 36 & 72 & 160 & -0.23 \\
\hline Difficulty sleeping for 2 or 3 nights after each treatment & 36 & 74 & 146 & -0.26 \\
\hline $\begin{array}{l}\text { Experiencing hair loss for several months during } \\
\text { treatment }\end{array}$ & 20 & 69 & 132 & -0.37 \\
\hline $\begin{array}{l}\text { Injection at doctor's office I time per week for } 3 \text { weeks } \\
\text { out of every month }\end{array}$ & 11 & 76 & 139 & -0.47 \\
\hline Pill once a week for 3 weeks out of every month & I & 121 & 139 & -0.86 \\
\hline Pill daily taken at home with water & 0 & 136 & 156 & -0.87 \\
\hline
\end{tabular}

levels of the attribute for OS ranged from 1 to 5 years in one study and 1 to 9 years in the other, which may have attributed to its high preference weight.

Preference weight is calculated as the difference between utility in the lowest and highest ranked levels of an attribute. The toxicity attribute only included generic "mild or moderate" versus "severe" side effects at various risk 
Table 4 Best-Worst Scaling Results - Caregivers

\begin{tabular}{|c|c|c|c|c|}
\hline Feature & $\begin{array}{c}\text { Frequency Picked } \\
\text { Most } \\
\text { Bothersome }\end{array}$ & $\begin{array}{c}\text { Frequency Picked } \\
\text { Least } \\
\text { Bothersome }\end{array}$ & $\begin{array}{c}\text { Number of } \\
\text { Times Item Was } \\
\text { Shown }\end{array}$ & Relative Score \\
\hline \multicolumn{5}{|l|}{ Caregivers $(\mathbf{N}=32)$} \\
\hline $\begin{array}{l}\text { Treatment damages kidneys and increases the risk of } \\
\text { kidney failure }\end{array}$ & 39 & 1 & 44 & 0.86 \\
\hline $\begin{array}{l}\text { Treatment weakens your bones and increases the risk } \\
\text { of a bone fracture }\end{array}$ & 26 & 4 & 45 & 0.49 \\
\hline $\begin{array}{l}\text { Treatment lowers white blood cell counts and increases } \\
\text { the risk of serious infection }\end{array}$ & 28 & 5 & 49 & 0.47 \\
\hline $\begin{array}{l}\text { Needing to go to the hospital to treat a side effect of } \\
\text { the treatment }\end{array}$ & 26 & 7 & 47 & 0.40 \\
\hline $\begin{array}{l}\text { Treatment weakens your immune system and you get } \\
\text { sick more often }\end{array}$ & 16 & 2 & 41 & 0.34 \\
\hline $\begin{array}{l}\text { Treatment lowers platelet counts and increases the risk } \\
\text { of bleeding problems }\end{array}$ & 20 & 6 & 44 & 0.32 \\
\hline $\begin{array}{l}\text { Having thinking or memory problems for a few weeks } \\
\text { after receiving treatment }\end{array}$ & 22 & 8 & 52 & 0.27 \\
\hline $\begin{array}{l}\text { Changes in mood that may include lack of patience or } \\
\text { nonstop talking for } 2 \text { or } 3 \text { days after each treatment }\end{array}$ & 16 & 10 & 43 & 0.14 \\
\hline Feeling exhausted or tired most days during treatment & 16 & 15 & 53 & 0.02 \\
\hline $\begin{array}{l}\text { 4-hour IV, I time per week for } 3 \text { weeks out of every } \\
\text { month }\end{array}$ & 13 & 14 & 55 & -0.02 \\
\hline $\begin{array}{l}\text { Experiencing hair loss for several months during } \\
\text { treatment }\end{array}$ & 14 & 19 & 45 & -0.11 \\
\hline $\begin{array}{l}\text { You need to travel } 3 \text { hours roundtrip once a week to } \\
\text { receive your treatment }\end{array}$ & 14 & 21 & 48 & -0.15 \\
\hline $\begin{array}{l}\text { Having trouble working at your job or at home during } \\
\text { treatment }\end{array}$ & 9 & 17 & 51 & -0.16 \\
\hline $\begin{array}{l}\text { I-hour IV, } 2 \text { times per week for } 3 \text { weeks out of every } \\
\text { month }\end{array}$ & 13 & 22 & 53 & -0.17 \\
\hline Difficulty sleeping for 2 or 3 nights after each treatment & 9 & 24 & 55 & -0.27 \\
\hline $\begin{array}{l}\text { Injection at doctor's office I time per week for } 3 \text { weeks } \\
\text { out of every month }\end{array}$ & 5 & 26 & 43 & -0.49 \\
\hline Pill once a week for 3 weeks out of every month & 0 & 37 & 43 & -0.86 \\
\hline
\end{tabular}

levels from 0 to $60 \%$ which we may suggest, from a clinical standpoint, is not on the same scale as a difference of 4 or 8 years in OS. In the current study, we did not include OS as an attribute and limited the absolute difference in the PFS attribute to 18 months largely due to this concern.

In the current study, the observed role of severe nerve damage as a driver of treatment preferences warrants further consideration. Both patients and caregivers were particularly averse to severe nerve damage, which was described to patient and caregiver respondents in the survey as "potentially limiting normal daily activities." Although avoiding 
severe nerve damage was important to both patients and caregivers in the study, it was especially so to patients, presumably because they are averse to the limitations that can result from serious nerve damage or because they wish to avoid burdening caregivers. Nerve damage is common with both proteasome inhibitors and immunomodulatory drugs. Bortezomib has the most associated neuropathy with $16 \%$ of those receiving intravenous treatment reporting severe neuropathy. Administered predominantly subcutaneously today, it is associated with a $6 \%$ incidence of severe neuropathy. ${ }^{25}$ With both administration routes, the nerve damage is largely reversible following discontinuation. Given the importance of severe nerve damage to respondents in this study, future research should explore other dimensions of nerve damage as drivers of treatment preferences, including whether such damage is permanent or temporary.

The results also suggest that patients and, potentially, caregivers both seemed to prefer oral drugs over injections, at least for some dosing schedules. Some studies of cancer therapy preferences that included mode of administration have found that patients prefer oral to intravenous administration, including the two aforementioned DCE studies in MM. ${ }^{23,24,26-30}$ Future research should explore how mode of administration influences patient preferences, perhaps separately from assessing benefit-risk tradeoffs between efficacy and adverse events. In such a study, a survey to evaluate treatment satisfaction and burden of illness among patients undergoing treatment for MM found that patients treated with oral therapy reported greater effectiveness, satisfaction, and convenience than patients treated with injectable therapy. ${ }^{31,33}$

The role of cost in patient and caregiver preferences is another interesting finding from this study. Although analyses of the impact of cost on treatment preferences is not as robust as the full DCE, there is a clear trend that suggests that cost is important to some patients when evaluating treatment options. Supporting this is evidence from a qualitative study that found financial impacts of treatment to be among patients' highest priorities for MM treatment. ${ }^{32}$

Interestingly, caregivers did not seem to alter treatment selection based on cost. This could suggest that cost is less important to caregivers than patients, but the small sample size in the caregiver cohort limits the potential generalizability of this finding. However, this finding was echoed in the Australian DCE where out-of-pocket costs were also more important to patients than caregivers. ${ }^{24}$ However, it must be noted that out-of-pocket costs were not highly important to either group, ranking behind OS, remission duration, mode/frequency of treatment and severe side effects. In the UK study, out-of-pocket costs was the least important of all attributes. ${ }^{23}$ While out-of-pocket cost is an important issue in health care worldwide, the differing results may suggest that cost-of-care is a more important issue for patient with MM in the US than in other countries.

Overall our results are very much in line with a recent study using an unbiased artificial intelligence- supported approached that showed that myeloma patients can be divided into two groups: one favoring PFS while the other preferring QoL (through minimizing toxicities). ${ }^{34}$ As proposed by the authors of that study, collection of both PFS and QoL data should both be considered to better understand and account for this heterogeneity in patients' preferences and assist the future treatment decision making process.

Some limitations of this study must be noted. The patient and caregiver samples are subject to selection bias, and the results may not be generalizable. In addition, preferences may vary by whether patients have newly diagnosed MM, have experienced a single relapse, or have experienced multiple relapses. Preferences also likely vary based on cultural norms across various countries and cultures. Further, the sample sizes may be insufficient to detect smaller differences in preferences between attribute levels. Lastly, as with all DCE, we must acknowledge that choices based on hypothetical treatments may not reflect real-world decisions that patients, caregivers, and doctors make.

\section{Conclusions}

Patients with relapsed or refractory MM and their caregivers consider many factors including efficacy, toxicity, mode/ frequency of administration, and cost in their decisions regarding treatment options. Discussion with patients and their caregivers about their priorities for treatment and the tradeoffs they are willing to make across different treatment attributes could promote shared decision-making and help improve treatment satisfaction. This work supports the need for larger, well-controlled studies of patient preferences in MM care. 


\section{Acknowledgments}

This work was funded in part by Millennium Pharmaceuticals, Inc., a wholly owned subsidiary of Takeda Pharmaceutical International Co., Cambridge, MA. Kimberly Moon of RTI Health Solutions provided project management for the analysis. Kate Lothman of RTI Health Solutions provided medical writing services.

\section{Disclosure}

Daniel Auclair reports grants from Takeda, during the conduct of the study performed at MMRF; he is now an AstraZeneca employee. Carol Mansfield and Brennan Mange are salaried employees of RTI Health Solutions which was contracted by Millennium Pharmaceuticals, Inc., a wholly owned subsidiary of Takeda Pharmaceutical International Co. to assist in the analysis and writing. Craig E Cole reports personal fees and/or grants from Oncopeptides, Sanofi, and GlaxoSmithKline, outside the submitted work. Jonathan L Kaufman reports grants and/or personal fees from Janssen, Amgen, AbbVie, Roche, Sutro, TG therapeutics, Incyte, BMS, and Tecnofarma, outside the submitted work. Jeffrey A Zonder reports personal fees and/or grants from Janssen, Takeda, Regeneron, Amgen, Intellia, Eidos, Alnylam, Oncopeptides, BMS, and Caelum, outside the submitted work. Mehul Dalal is a salaried employee of Millennium Pharmaceuticals, Inc., a wholly owned subsidiary of Takeda Pharmaceutical International Co. Joseph R Mikhael has received honoraria from Amgen, BMS, GSK, Karyopharm, Celgene, Janssen, Sanofi, and Takeda Pharmaceuticals. David S Siegel has received honoraria from Amgen, BMS, GSK, Celgene, Janssen, Karyopharm and Takeda Pharmaceuticals.

The authors report no other conflicts of interest in this work.

\section{References}

1. National Cancer Institute Surveillance, Epidemiology, and End Results Program (NCI SEER). Cancer stat facts: multiple myeloma. Available from: https://seer.cancer.gov/statfacts/html/mulmy.html. Accessed June 3, 2019.

2. Kazandjian D. Multiple myeloma epidemiology and survival: a unique malignancy. Semin Oncol. 2016;43(6):676-681. doi:10.1053/j. seminoncol.2016.11.004

3. Nielsen LK, Jarden M, Andersen CL, Frederiksen H, Abildgaard N. A systematic review of health-related quality of life in longitudinal studies of myeloma patients. Eur J Haematol. 2017;99(1):3-17. doi:10.1111/ejh.12882

4. Hiasa M, Okui T, Allette YM, et al. Bone pain induced by multiple myeloma is reduced by targeting V-ATPase and ASIC3. Cancer Res. 2017;77 (6):1283-1295. doi:10.1158/0008-5472.CAN-15-3545

5. Heher EC, Rennke HG, Laubach JP, Richardson PG. Kidney disease and multiple myeloma. Clin J Am Soc Nephrol. 2013;8(11):2007-2017. doi: $10.2215 /$ CJN.12231212

6. Tzoran I, Brenner B, Hoffman R. Myeloma and thrombotic complications. Minerva Med. 2013;104(2):155-160.

7. Boland E, Eiser C, Ezaydi Y, Greenfield DM, Ahmedzai SH, Snowden JA. Living with advanced but stable multiple myeloma: a study of the symptom burden and cumulative effects of disease and intensive (hematopoietic stem cell transplant-based) treatment on health-related quality of life. J Pain Symptom Manage. 2013;46(5):671-680. doi:10.1016/j.jpainsymman.2012.11.003

8. Muehlbacher AC, Berndt K, Schreder CH, Nuebling M. Patients' preferences in multiple myeloma treatment: what do physicians think? Blood. 2008;112(11):2366. doi:10.1182/blood.V112.11.2366.2366

9. Mian HS, Fiala MA, Wildes TM. Burden of treatment among older adults with newly diagnosed multiple myeloma. Clin Lymphoma Myeloma Leuk. 2020. doi:10.1016/j.clml.2020.09.010

10. Deniz H, Inci F. The burden of care and quality of life of caregivers of leukemia and lymphoma patients following peripheric stem cell transplantation. J Psychosoc Oncol. 2015;33(3):250-262. doi:10.1080/07347332.2015.1019660

11. Multiple Myeloma Research Foundation (MMRF). MMRF CoMMpass Study. Available from: https://themmrforg/we-are-curing-multiple-mye loma/mmrf-commpass-study/. Accessed November 7, 2019.

12. Bridges JF, Hauber AB, Marshall D, et al. Conjoint analysis applications in health-a checklist: a report of the ISPOR good research practices for conjoint analysis task force. Value Health. 2011;14(4):403-413. doi:10.1016/j.jval.2010.11.013

13. Chrzan K, Orme B. An overview and comparison of design strategies for choice-based conjoint analysis. Technical Paper Series. Sawtooth Software Inc; 2000.

14. Kuhfeld W. Marketing Research Methods in SAS: Experimental Design, Choice, Conjoint, and Graphical Techniques. Cary (NC): SAS Institute Inc.; 2010.

15. Kuhfeld W. Efficient experimental designs using computerized searches. Sawtooth Software Conference Proceedings; 1997:71-86.

16. Kuhfeld W, Tobias F, Garratt M. Efficient experimental design with marketing research applications. J Mark Res. 1994;31:545-557. doi:10.1177/ 002224379403100408

17. Sawtooth Software Inc. CBC User Manual. Sequim: Sawtooth Software; 1999.

18. Train K. Discrete Choice Methods with Simulation. Cambridge (UK): Cambridge University Press; 2009.

19. Train K, Sonnier G. Mixed logit with bounded distributions of correlated partworths. In: Scarpa R, Alberini A, editors. Applications of Simulation Methods in Environmental and Resource Economics. Dordrecht: Springer Publisher; 2005:117-134.

20. Hauber AB, González JM, Groothuis-Oudshoorn CG, et al. Statistical methods for the analysis of discrete choice experiments: a report of the ISPOR conjoint analysis experimental design task force. Value Health. 2016;19(4):300-315. doi:10.1016/j.jval.2016.04.004 
21. Food and Drug Administration (FDA). Prescription Drug User Fee Act (PDUFA) VI. Available from: https://www.fda.gov/ForIndustry/UserFees/ PrescriptionDrugUserFee/. Accessed June 25, 2018.

22. Food and Drug Administration (FDA). 21st century cures act; 2018. Available from: https://www.fda.gov/RegulatoryInformation/ LawsEnforcedbyFDA/SignificantAmendmentstotheFDCAct/21stCenturyCuresAct/default.htm. Accessed June 25, 2018.

23. Fifer S, Galinsky J, Richard S. Myeloma patient value mapping: a discrete choice experiment on myeloma treatment preferences in the UK. Patient Prefer Adherence. 2020;14:1283-1293. doi:10.2147/PPA.S259612

24. Fifer SJ, Ho KA, Lybrand S, Axford LJ, Roach S. Alignment of preferences in the treatment of multiple myeloma - a discrete choice experiment of patient, carer, physician, and nurse preferences. BMC Cancer. 2020;20(1):546. doi:10.1186/s12885-020-07018-6

25. Moreau P, Pylypenko H, Grosicki S, et al. Subcutaneous versus intravenous administration of bortezomib in patients with relapsed multiple myeloma: a randomised, Phase 3, non-inferiority study. Lancet Oncol. 2011;12(5):431-440. Erratum in: Lancet Oncol. 2011 Jun;12(6):522.PMID: 21507715. doi:10.1016/S1470-2045(11)70081-X

26. Mansfield C, Ndife B, Chen J, Gallaher K, Ghate S. Patient preferences for treatment of metastatic melanoma. Future Oncol. 2019;15(11):12551268. doi: $10.2217 /$ fon-2018-0871

27. Mansfield C, Masaquel A, Sutphin J, et al. Patients' priorities in selecting chronic lymphocytic leukemia treatments. Blood Adv. 2017;1(24):21762185. doi:10.1182/bloodadvances.2017007294

28. Eek D, Krohe M, Mazar I, et al. Patient-reported preferences for oral versus intravenous administration for the treatment of cancer: a review of the literature. Patient Prefer Adherence. 2016;10:1609-1621. doi:10.2147/PPA.S106629

29. Bridges JF, Mohamed AF, Finnern HW, Woehl A, Hauber AB. Patients' preferences for treatment outcomes for advanced non-small cell lung cancer: a conjoint analysis. Lung Cancer. 2012;77(1):224-231. doi:10.1016/j.lungcan.2012.01.016

30. Wilke T, Mueller S, Bauer S, et al. Treatment of relapsed refractory multiple myeloma: which new PI-based combination treatments do patients prefer? Patient Prefer Adherence. 2018;12:2387-2396. doi:10.2147/PPA.S183187

31. Chari A, Romanus D, DasMahapatra P, et al. Patient- reported factors in treatment satisfaction in patients with relapsed/refractory multiple myeloma (RRMM). Oncologist. 2019;24(11):1479-1487. doi:10.1634/theoncologist.2018-0724

32. Parsons JA, Greenspan NR, Baker NA, McKillop C, Hicks LK, Chan O. Treatment preferences of patients with relapsed and refractory multiple myeloma: a qualitative study. BMC Cancer. 2019;19(1):264. doi:10.1186/s12885-019-5467-x

33. Romanus D, DasMahapatra P, Hoole M, et al. Treatment satisfaction and burden of illness with oral vs injectable therapy in patients with relapsed/ refractory multiple myeloma (RRMM). Poster presented at the International Society for Pharmacoeconomics and Outcomes Research (ISPOR) 22nd Annual International Meeting; May 20-24, 2017; Boston, Massachusetts.

34. Fleischer A, Heimeshoff L, Allgaier J, et al. Is PFS the right endpoint to assess outcome of maintenance studies in multiple myeloma? Results of a patient survey highlight quality-of-life as an equally important outcome measure. Blood. 2021;138(Suppl. 1):836. doi:10.1182/ blood-2021-152648

\section{Publish your work in this journal}

Patient Preference and Adherence is an international, peer-reviewed, open access journal that focusing on the growing importance of patient preference and adherence throughout the therapeutic continuum. Patient satisfaction, acceptability, quality of life, compliance, persistence and their role in developing new therapeutic modalities and compounds to optimize clinical outcomes for existing disease states are major areas of interest for the journal. This journal has been accepted for indexing on PubMed Central. The manuscript management system is completely online and includes a very quick and fair peer-review system, which is all easy to use. Visit http://www.dovepress.com/testimonials.php to read real quotes from published authors.

Submit your manuscript here: https://www.dovepress.com/patient-preference-and-adherence-journal 